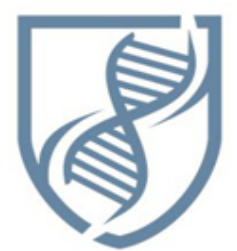

Journal of Bioscience and Applied Research
JBAAR

WWW.JBAAR.ORG

\title{
Apoptotic marker alternations in the spleen of experimentally hyperthyroid and hypothyroid rat
}

\author{
Ezar Hafez; Ahmed Masoud; Magdy Barnous; Ehab Tousson \\ Zoology Department, Faculty of Science, Tanta University, Tanta 31527, Egypt \\ Corresponding author e.mail. ezarhazaa1000@yahoo.com-
}

\begin{abstract}
Apoptosis plays a critical role in the development and homeostasis of multicellular organisms, especially those with high cell turnover such as the lymphoid system. The current study aimed to examined the effects of changes in thyroid hormones on apoptosis of spleen in male rats. 30 rats were equally divided into three groups (10 animals each). $G_{1}$, control group in which animals did not received any treatment; $G_{2}$, Hypothyroid group in which rats received $0.05 \%$ 6-n-propyl-2-thiouracil (PTU) in drinking water for 6 weeks; $G_{3}$, Hyperthyroid group in which rats received $100 \mu \mathrm{g} / \mathrm{Kg}$ L-Thyroxin sodium administration in drinking water for 6 weeks. In the present study; serum $\mathrm{T}_{3}$ and $\mathrm{T}_{4}$ concentrations were depressed and serum TSH concentration was significantly elevated in rats receiving PTU-induced hypothyroidism. On the other hand; serum $\mathrm{T}_{3}$ and $\mathrm{T}_{4}$ concentrations were significantly elevated and serum TSH concentration was depressed in rats receiving L-Thyroxin sodium-induced hyperthyroidism. In the current study; spleen in both hypothyroid and hyperthyroid rats revealed many of abnormalities as marked disruption of spleen structure, loss in distinction between the white and red pulps, degeneration and vacuolation with an increased in the lymphocyte population. Also, a significant increase in p53 and Caspase 3 apoptotic cells and a significant decrease in Bcl-2 antiapoptotic cells in the spleen tissues revealed the possibility of the apoptosis occurrence after PTU or Thyroxin administration in the case of hypothyroidism and hyperthyroidism.
\end{abstract}

Keywords: Hypothyroidism, Hyperthyroidism, Rats, Kidney, Liver, Testes, Spleen, Heart.

\section{Introduction}

Thyroid hormones regulate all metabolic activities such as growth rate, digestion strength, cholesterol secretion in the bile, respiration, oxygen consumption, heart rate, sodium/potassium pump, blood pressure lipid, carbohydrate and protein, metabolism and the actions of other lymphoid organs (Toshihiro, 2010; Ali et al., 2013; Ibrahim et al., 2011, 2012; Salama et al., 2013; Hafez and Tousson, 2014; Mohamed et al., 2014; Tousson et al., 2011a, 2012a-c, 2013, 2014a).

It is well known that thyroid hormones contribute to the development and maintenance of homeostasis in multicellular organisms to control cell growth and differentiation (Gandrillon et al., 1994; Oppenheimer et al., 1996; Mihara et al., 2003). Apoptosis plays a very important role in regulating a variety of diseases that have enormous social impacts. For example, schizophrenia is a neurodegenerative disease that may result from an abnormal ratio of pro- and anti-apoptotic factors (Glantz et al., 2006; Tousson et al., 2014b).

There is some evidence that this defective apoptosis may result from abnormal expression of $\mathrm{Bcl}-2$ and increased expression of caspase-3 (Glantz et al., 2006). It has been reported that thyroid hormone induces apoptotic cell death of differentiating erythrocytic progenitor cells (Mihara et al., 2003). On the contrary, thyroid hormone inhibits apoptosis of early differentiating cerebellar granule neurons by inducing enhanced expression of antiapoptotic Bcl-2 protein (Mihara et al., 2003).

The Spleen is one of the major target organ for thyroid hormone action and marked changes occur in spleen 
function in the case of hypo- or hyperthyroidism. Cell death during amphibian metamorphosis (involving apoptosis) is under the control of thyroid hormones (Tata, 1994; Ishizuya, 1996; Mihara et al., 2003).

When the cells expose to the external damage stimuli they activate the regulation of expression of these genes. P53 tumor suppressor protein is a transcription factor that regulates the transcription rate of several genes involved in the regulation of cells cycle, DNA repair and apoptosis (Wang et al., 2005; Tousson et al., 2011b, 2012d, 2014b, 2014d). Expressed p53 negatively delays cell cycle progression that leads to the apoptosis if the damage cannot be repaired (Yonish-Rouach et al., 1993). P53 acts as a protector of genomic activity by inducing either cell cycle arrest (at G1 and/or G2 phase) or apoptosis (Collavin et al., 2010; Tousson et al., 2012d).

Bc1-2 gene is an anti-apoptotic protein that have an important roles in regulating cell survival and apoptosis (Cory and Adams, 2002; Tousson et al., 2014a, 2014d). A high level of Bcl-2 expression prevents cells from apoptosis caused by cytotoxic factors or cellular stress (Cory et al., 2003). Caspase-3 belongs to a family of evolutionally conserved cysteine proteases that play a key role in regulating programmed cell death, or apoptosis (Degterev, 2003; Huang et al., 2011). Two main apoptosis activation pathways are the extrinsic and the intrinsic pathways. The extrinsic pathway is activated by the binding of ligands (including TNF $\alpha$, FasL, and TRAIL) to cell-surface receptors, while the intrinsic pathway is typically activated in response to DNA or cellular damage. The convergence of the extrinsic and intrinsic pathways occurs at the proteolytic activation of caspase-3 (Fulda et al., 2006; Porter, 2006). Once caspase-3 is activated, a series of irreversible events are set in motion that lead to the death of the cell, including activation of the CAD endonuclease that degrades DNA within the nucleus and initiates chromatin condensation (Elmore, 2007).

There is little information about the relation between hyperthyroidism, hypothyroidism and apoptotic markers expression. So, the present study represents a contribution to declare the apoptotic marker alternations in the spleen of experimentally hyperthyroid and hypothyroid rat.

\section{Materials and Methods}

\section{Experimental animals \& study design}

The experiment was performed on 30 male albino rats (Rattus norvigicus) weighing $140 \mathrm{~g}( \pm 10)$ and of 8-9 weeks' age. They were obtained from laboratory farms, Zoology Department, Faculty of Science, Tanta University, Egypt. The rats were kept in the laboratory for one week before the experimental work and maintained on a standard rodent diet composed of $20 \%$ casein, $15 \%$ corn oil, $55 \%$ corn starch, 5\% salt mixture and 5\% vitaminzed starch (Egyptian Company of Oils and Soap, Kafr-Elzayat, Egypt), and water available ad libitum. The temperature in the animal room was maintained at $23 \pm 2{ }^{\circ} \mathrm{C}$ with a relative humidity of $55 \pm 5 \%$. Light was on a 12:12 hr light-dark cycle. All the experiments were done in compliance with the guiding principles in the care and use of laboratory animals. The rats were equally divided into three groups (10 rats each).

Group 1: Control group in which rats never received any treatment (euthyroid).

Group 2: Hypothyroid group in which a chemical experimental rat model of hypothyroidism that mimics hypothyroidism in humans has been developed. Rats received $0.05 \%$ 6-n-propyl-2-thiouracil (PTU; Amoun Pharmaceutical Chemicals Co., Egypt) in drinking water for 6 weeks (Tousson et al., 2011a).

Group 3: Hyperthyroid group in which a chemical experimental rat model of hyperthyroidism that mimics hyperthyroidism in humans has been developed. Rats received L-Thyroxin sodium administration $(100 \mu \mathrm{g} / \mathrm{Kg}$, GSK Pharmaceutical Chemicals Co., USA) in drinking water for 6 weeks (Tousson et al., 2013).

At the end of the experimental period, rats from each group were euthanized with anesthetic ether and subjected to a complete necropsy after 10-12 hr of fasting. Spleen were removed, carefully cleaned from adhering connective tissue in cold saline and weighed. Blood samples were individually collected in plain tubes from each rat from the orbital sinus vein. Blood allowed to clot at $37^{\circ} \mathrm{C}$ for 15 minutes and then centrifuged at $4000 \mathrm{rpm}$ for 10 minutes. The serum obtained was then separated and divided to several aliquots to be thawed only once on demand and stored at $-20^{\circ} \mathrm{C}$ for determination serum total triiodothyronine hormone $\left(\mathrm{T}_{3}\right)$ concentration, serum thyroxine hormone (T4) concentration and serum thyroid stimulating hormone (TSH) concentrations according to the methods of Maes et al. (1997); Thakur et al. (1997) and Mandel et al. (1993) respectively. The kits for T4, T3 and TSH were obtained from Calbiotech INC (CBI), USA.

\section{Histological investigation:}

Five rats from each group were used for the histopathological and immunohistochemical studies. Spleen were immediately removed from the dissected rats and divided transversely into two parts and immediately one part fixed by immersion in $10 \%$ buffered formalin solution and left for 24-48 h. The specimens were then dehydrated, cleared and embedded in paraffin. Serial sections of $5 \mathrm{~mm}$ thick were cut using mean of rotary microtome and stained with Haematoxylin and eosin (H\&E) according to the method of Bancroft and Cook (1994).

\section{Immunohistochemical detection of p53, Bc1-2 and activated caspase- 3 :}

Expression of p53, Bc1-2 and caspase-3 immunoreactivities (p53-ir, Bc1--ir2 and Casp3-ir) was detected using avidin Biotin Complex (ABC) method (Sternberger, 1979; Tousson et al., 2012d, 2014d). Paraffin sections $(5 \mathrm{~m}$ thick) of fixed rat hearts that mounted on 
gelatin chromalum-coated glass slides were dewaxed and rehydrated sections were washed in distilled water for 5 min, rinsed in PBST for $10 \mathrm{~min}$ and incubated with $10 \%$ normal goat serum for $15 \mathrm{~min}$ to reduce non-specific background staining. Then, the sections were incubated with anti-rabbit p53 or anti-rabbit Bc1-2 or anti-rabbit casp3 (monoclonal antibody (Dako, 1:80, 1:2000 and $1: 100$, respectively) for 2 hours at room temperature (Tousson et al., 2014b, 2014c).

The sections after 5 baths in PBST were incubated with biotinylated goat antirabbit immuoglobulin (Nichirei, Tokyo, Japan). The sections after 5 baths in PBST were further incubated with Avidin Biotin Complex (ABC: Nichirei, Tokyo, Japan) for 1 hour at room temperature. The reaction was developed by using $20 \mathrm{mg} 3-3^{\prime}-$ diaminobenzidine tetrahydrochloride (DAB, Wako pure chemical industries, Ltd) in $40 \mathrm{ml}$ PBST, pH 7.2 containing $10 \mathrm{ml}$ of hydrogen peroxide $\left(\mathrm{H}_{2} \mathrm{O}_{2}\right)$ for $8 \mathrm{~min}$ at a dark room followed by distilled water then dehydrated and mounted. The criterion for a positive reaction confirming the presence of p53, Bcl-2 and Casp3 is a dark, brownish, intra cytoplasmic precipitate. For the negative control, the primary antibody was omitted to guard against any false positive results which might develop from a nonspecific reaction. Brightness, contrast were adjusted using Adobe Photoshop software. Image analysis was adjusted using PAX-it image analysis software. The data was statistically analyzed using SPSS statistical version 16 software package (SPSS ${ }^{\circledR}$ Inc., USA).

Data were expressed as mean values \pm SD and statistical analysis was performed using one-way analysis of variance (ANOVA) followed by the Least Significant Difference (LSD) tests to assess significant differences among treatment groups. The criterion for statistical significance was set at $\mathrm{p}<0.01$. All statistical analyses were performed using SPSS statistical version 16 software package (SPSS ${ }^{\circledR}$ Inc., USA).

\section{Results}

In order to ensure that PTU induced hypothyroidism and LThyroxin sodium induced hyperthyroidism we determined the serum $\mathrm{T}_{3}, \mathrm{~T}_{4}$ and $\mathrm{TSH}$ through the dose period. Figures (1-3) showed that the serum $\mathrm{T}_{3}, \mathrm{~T}_{4}$ and $\mathrm{TSH}$ levels in hypothyroid and hyperthyroid rats. $\mathrm{T}_{3}$ was significantly decrease in Hypothyroid rats $(26.25 \pm 1.59)$ when compared with control rat group $(46.6 \pm 2.53)$ while was significantly increase in hyperthyroid rats $(94.55 \pm 4.77)$ when compared with control rat group $(46.6 \pm 2.53) . \mathrm{T}_{4}$ was significantly decrease in Hypothyroid rats $(1.31 \pm 0.27)$ when compared with control rat group $(2.87 \pm 0.046)$ while was significantly increase in hyperthyroid rats $(5.88 \pm 0.17)$ when compared with control rat group $(2.87 \pm 0.046)$.

TSH was significantly increase in Hypothyroid rats $(3.94 \pm 0.86)$ when compared with control rat group $(1.32 \pm 0.14)$ while was significantly decrease in hyperthyroid rats $(0.03 \pm 0.005)$ when compared with control rat group $(1.32 \pm 0.14)$.

T3

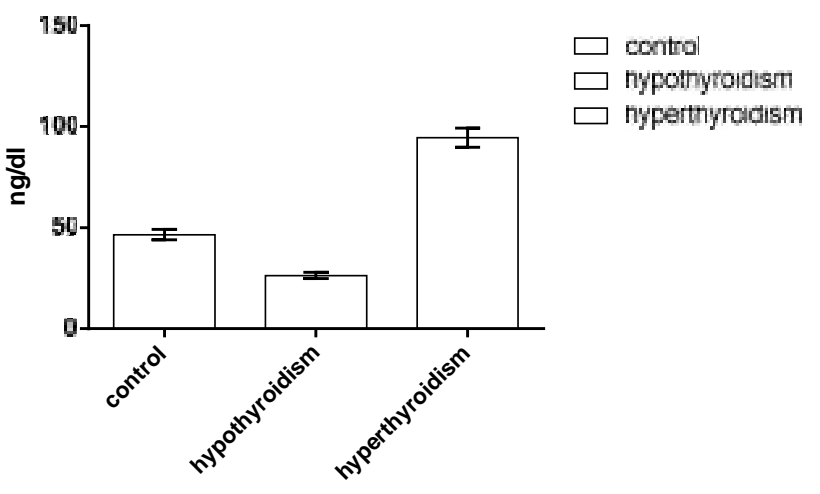

Figure 1: Changes in Serum total triiodothyronine hormone $\left(\mathrm{T}_{3}\right)$ concentration in different group under study.

T4

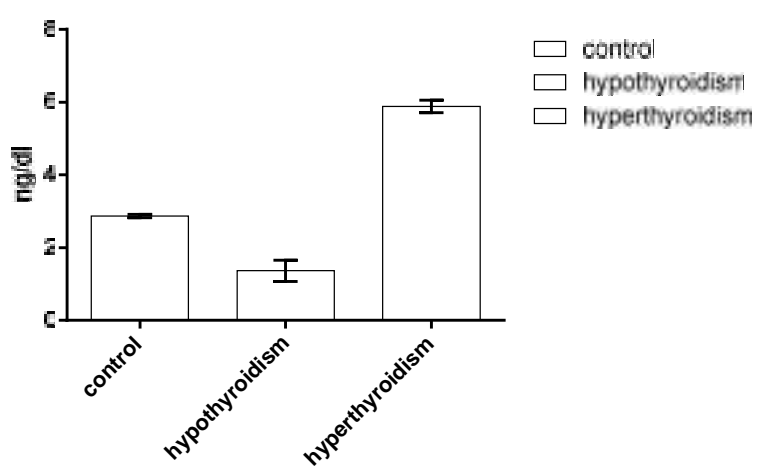

Figure 2: Changes in serum thyroxine hormone (T4) concentration in different group under study.

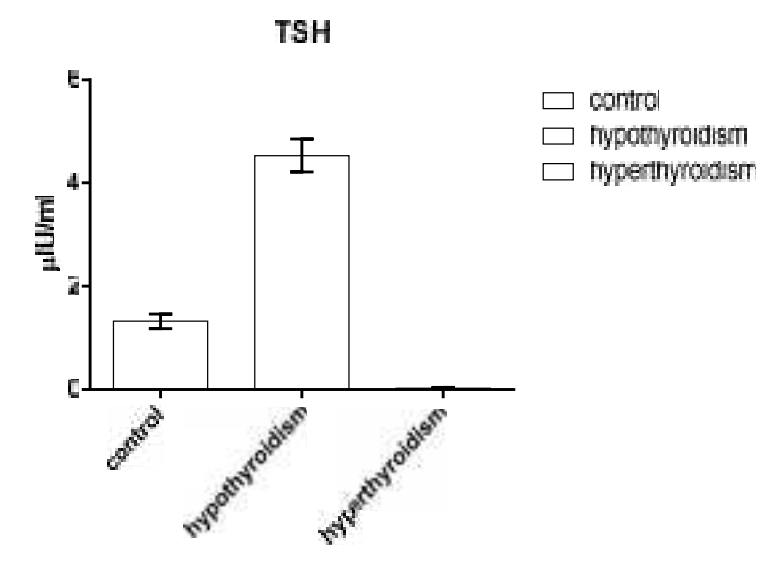

Figure 3: Changes in serum thyroid stimulating hormone (TSH) concentration in different group under study. 
Sections of spleen in the control rat group appear to consist of two main compartments, the white and the red pulps. The red pulp occupies the distance between the white pulps (Figure 4A). The white pulp is so named because of its content of deeply basophilic lymphocyte aggregation, and it is composed of two main parts, the splenic follicles and the marginal zone.

The splenic follicles are big, and contain eccentric arterioles (Figure 4A), and they are subdivided into an inner periarterial lymphatic sheath, where T-lymphocytes predominate, and an outer periarterial lymphatic sheath, where B lymphocytes predominate. The red pulp is composed of a meshwork of splenic cords and the splenic sinusoids (vascular channels).

The splenic cords consist of the reticular cells and associated macrophages. In addition, large-sized and rough spherical bodies of megakaryocytes (MK) are observed. These bodies contain large irregular multilobulated nuclei, having clumps of dispersed chromatin and they have an extensive homogenous cytoplasm (Figure 4A).
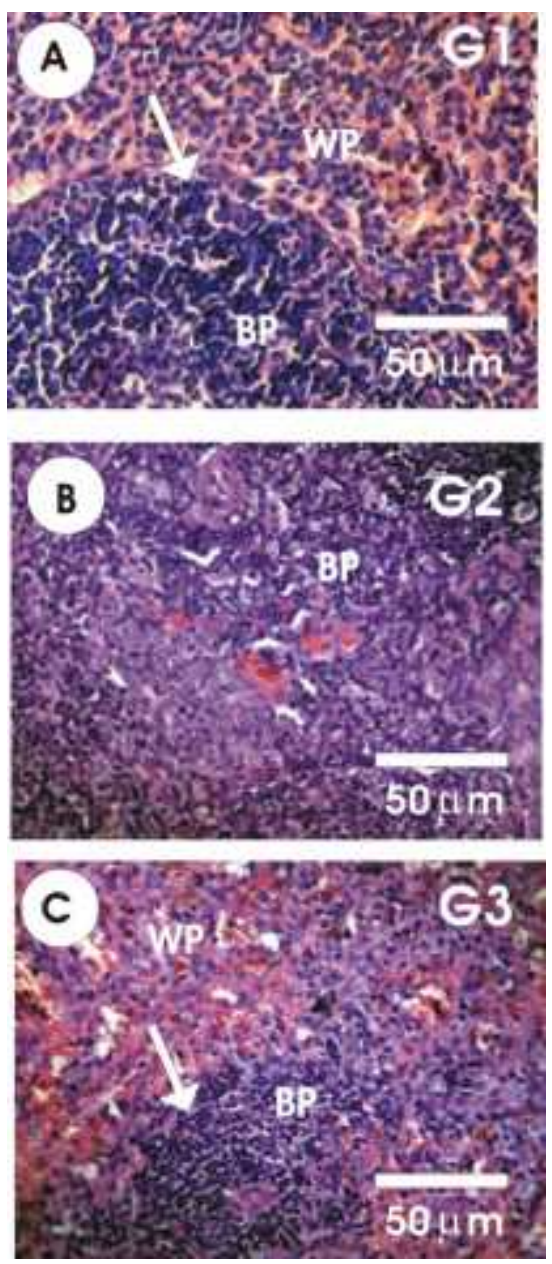

Figure 4. A-C: Photomicrographs of the rat spleen sections stained with H\&E. A: Spleen section in control showed normal histological structures. Spleen consist of two main compartments, the white (WP) and the red pulps (BP). B:
Spleen section in hypothyroid rat (G2) showed mild degeneration and vacuolation with mild loss in distinction between the white and red pulps. C: Spleen section in hyperthyroid rat showed a mild loss in distinction between the white and red pulps, cellular degeneration, vasodilatation and congestion of splenic sinusoids and marked decrease in the lymphocyte population.

Spleen sections in hypothyroid rat revealed marked disruption of spleen structure, and many signs of pathological alterations were observed as tissue degeneration and vacuolation with marked loss in distinction between the white and red pulps (Figure 4B). An increased in the lymphocyte population with marked loss in the chromatin of their nuclei. An increase in the number of inflammatory cell components which were polymorphous in structure (Figure 4B).

Spleen sections in hyperthyroid rat, a marked disruption of spleen structure, and many signs of pathological alterations were observed. These alterations include the mild loss in distinction between the white and red pulps (Figure 4C); the decrease in the lymphocyte population with marked loss in the chromatin of their nuclei. Vasodilatation and congestion of splenic sinusoids were seen in the red pulp, and there was an increase number of inflammatory cell components which were polymorphous in structure, and they can be seen in layers. Most of the lymphocytes contained pyknotic nuclei (Figure 4C).

\section{P53 immunoreactivity in rat spleen tissue:}

Figures (5A-5C) and Table (1) showed the detection and distribution of p53 immunoreactivity (P53-ir) in the spleen in the different groups under study. P53 is a nuclear phosphoprotein which acts as a tumor suppressor.

Spleen in control group showed finite reaction for p53-ir (grade 1) in white pulps, while no reaction for p53-ir red pulps (Figures 5A). In contrast, mild to moderate p53-ir positive reaction (grade 3 ) were observed in white pulps in the hypothyroid rat spleen section (Figures 5B). On the other hand; moderate positive reactions for p53-ir (grade 4) were observed in spleen section in hyperthyroid rat (Figures 5C).

\section{Bcl2 immunoreactivity in rat spleen tissue:}

Figures (6A-6C) and Table (1) show the detection and distribution of Bcl2-ir immunoreactivity (Bcl2-ir) in the spleen tissues in the different groups under study. Spleen section in control group showed marked positive reaction for Bcl2-ir (grade 4) in white pulps and a faint reaction for $\mathrm{Bcl} 2$-ir (grade 1) in the red pulps (Figures 6A). section. Mild positive reactions for $\mathrm{BCl} 2$-ir (grade 2) were observed in the spleen section in hypothyroid rat while the intensity of $\mathrm{BCl} 2$-ir were increased to moderate reactions in hyperthyroid rat spleen section (Figures 6B\&6C).

\section{Caspase 3 immunoreactivity in rat spleen tissue:}

Figures (7A-7C) and Table (1) show the detection and distribution of Bcl2-ir immunoreactivity (Casp3-ir) in the 

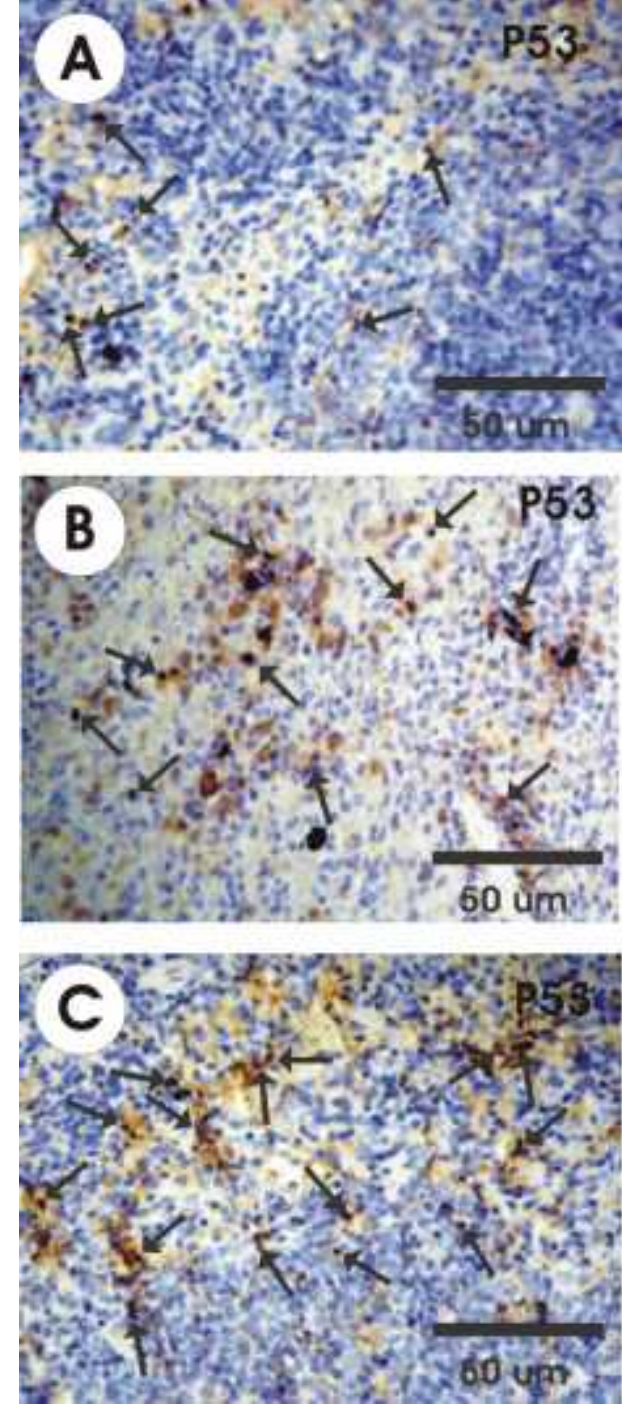

Figures 5(A-C): A-C High power micrographs of the spleen sections of rat stained by P53-ir. A: Faint p53-ir positive reaction (grade 1) in control rat spleen section. B: Mild to moderate p53-ir positive reaction (grade 3) in hypothyroid rat spleen section. C: Moderate positive reactions for p53-ir (grade 4) in hyperthyroid rat spleen section.

spleen tissues in the different groups under study. Spleen section in control group showed faint to mild positive reaction for Casp3-ir (grade 1) in both white and red pulps (Figure 7A). Mild positive reactions for Casp3-ir (grade 2) were observed in the spleen section in hypothyroid rat in both white and red pulps (Figure 7B). On the other hand; marked positive reactions for Casp3-ir (grade 4) in hyperthyroid rat spleen section were observed in both white and red pulps (Figure 7C).

\section{Discussion}

The present study was designed to investigate the effect of thyroid dysfunctions (hypothyroidism and hyperthyroidism) and apoptotic markers (P53, Bcl2 and Caspase 3 immunoreactivities) on rat spleen. In order to achieve this target we made a hypothyroid state by using a reversible PTU (Tousson et al., 2012a, 2012c) and we made a hyperthyroid state by using L-Thyroxin sodium administration (Tousson et al., 2013). PTU has been used as an anti-thyroid agent, because of its specific and wellcharacterized mode of action (Gilbert and Paczkowski, 2003; Ahmed et al., 2010). PTU is an anti-thyroid drug which inhibits both the synthesis of thyroid hormones in the thyroid gland, and the conversion of thyroxine $\left(\mathrm{T}_{4}\right)$ to its active form, triiodothyronine $\left(\mathrm{T}_{3}\right)$, in peripheral tissues. In order to ensure the hypothyroid state we regularly determined the serum $\mathrm{T}_{3}, \mathrm{~T}_{4}$ and $\mathrm{TSH}$ through the dose period where serum $T_{3}$ and $T_{4}$ concentrations is depressed and serum TSH concentration is significantly elevated in rats receiving PTU-induced hypothyroidism. On the other hand; in order to ensure the hyperthyroid state we regularly determined the serum $\mathrm{T}_{3}, \mathrm{~T}_{4}$ and $\mathrm{TSH}$ where serum $\mathrm{T}_{3}$ and $\mathrm{T}_{4}$ concentrations is significantly elevated and serum TSH concentration is depressed in rats receiving L-Thyroxin sodium-induced hyperthyroidism. In the present study; TSH were significantly increase in hypothyroid and significantly decrease in hyperthyroid rats; this result coincides with studies of Shibutani et al. (2009); Ibrahim et al. (2011, 2012); Tousson et al. (2011a, 2013, 2014a); Hafez and Tousson (2014).

The previous studies indicate that hypo and hyperthyroidism causes oxidative tissue damage by increasing lipid peroxidation in tissues and decreasing the level of antioxidant enzymes (Ibrahim et al., 2012; Ali et al., 2013; Salama et al., 2013; Tousson et al., 2012b, 2012c, 2013). In the current study; spleen in both hypothyroid and hyperthyroid rats revealed many of abnormalities as marked disruption of spleen structure, loss in distinction between the white and red pulps, degeneration and vacuolation with an increased in the lymphocyte population and in the number of inflammatory cell components. So, spleen structure were changes in the hypothyroidism and hyperthyroidism. This result coincides with studies of Cano-Europa et al. (2008, 2011) who reported that; Methimazole-induced hypothyroidism causes cellular damage in the spleen, heart, liver, lung and kidney. Previous studies have demonstrated that antithyroidinduced hypothyroidism can cause cellular damage (Tousson et al., 2012a, 2012b).

Apoptosis, or programmed cell death, is a crucial cellular activity in the behavior of mammalian cells in a wide range of pathophysiological conditions. It is responsible for the deletion of unwanted cells. Apoptosis of individual cells may present a protective mechanism against neoplastic development in the organism by eliminating genetically damaged cells (Wang et al., 2005; Tousson et al., 2011b; 2014d). When the cells expose to the external damage stimuli they activate the regulation of expression of these genes. P53 tumor suppressor protein is a transcription factor that regulates the transcription rate of several genes involved in the regulation of cells cycle, DNA repair and apoptosis (Wang et al., 2005; Tousson et al., 2011b). P53 acts as a protector of genomic activity by inducing either 
cell cycle arrest (at G1 and/or G2 phase) or apoptosis. So, it and neurotransmitters and adenosinergic system comes to the forefront of apoptosis researches (Wang et al., interactions. Intern J Devl Neuroscience 28: $437-454$.

2003; Collavin et al., 2010).

Ali E, Ibrahim W, Ashraf RM and Tousson E (2013) In the current study, the expression of the cytoplasmic p53, Interrelationship of heme oxygenase and the oxidative caspase 3 and the incidence of the apoptotic cells were very stress in the cardiac tissues of thyroidectomized rats. low in the control spleen sections, in contrast to Bcl2 were Pharmacologia, 4(12): 623-633.

very high in in the control spleen sections. A high level of Bcl-2 expression prevents cells from apoptosis caused by cytotoxic factors or cellular stress (Cory et al., 2003). Our immunohistochemical observations of the spleen tissues showed a significant increase of the apoptotic protein p53 and Caspase 3 and a significant decrease in the antiapoptotic Bc1-2 proteins in both hypo- and hyperthyroidism. When there is an excess of anti-apoptotic proteins, the cells are more resistant to apoptosis (Scorrano and Korsmeyer, 2003). Bc1-2 gene is an anti-apoptotic protein and it has important roles in regulating cell survival (Tousson et al., 2014a). A high level of Bcl-2 expression prevents cells from apoptosis caused by cytotoxic factors or cellular stress (Cory and Adams, 2002; Cory et al., 2003).

This protein has a role in governing the release of cytochrome $\mathrm{c}$ from the mitochondria (Cory et al., 2003). So, it is important in protecting the cell against the apoptosis without affecting cell proliferation. When there is an excess of anti-apoptotic proteins, the cells are more resistant to apoptosis (Scorrano and Korsmeyer, 2003). Although Diebold et al (1996) failed to reveal any correlation between the expressions of these two proteins. In contrast; Tousson et al. (2014d) success to find the relation between P53 and $\mathrm{Bcl} 2$. Also an inverse correlation was found between the expression of $\mathrm{Bcl}-2$ and in both $\mathrm{p} 53$ and caspase 3 proteins in our results. So, the increasing of p53 and Caspase 3 apoptotic cells and the decreasing Bcl-2 antiapoptotic cells in the present study reveal the possibility of the apoptosis occurrence after PTU or Thyroxin administration in the case of hypothyroidism and hyperthyroidism. These findings are compatible with the results of other studies (Lo'pez-Torres et al., 2000; Mahfoud et al., 2010 and Tousson et al., 2011a, 2011b). In the present study, Our results are in agreement with a number of recent studies which provided evidence that hypothyroidism causes an adverse effect on the human health (Woeber, 2002; Cano-Europe, 2008; Tousson et al., 2011b, 2014d).

Conflicts of interest The authors had no conflicts of interest to declare in relation to this article. This research received no specific grant from any funding agency in the public, commercial, or not-for-profit sectors

Author contributions: Ehab Tousson designed and Ezar Hafez and Ahmed Masoud conducted the experiments. Ehab Tousson, Ezar Hafez and Magdy Barnous wrote the manuscript. All authors have contributed equally to this article.

\section{References}

Ahmed OM, Abd El-Tawab SM, Ahmed RG (2010) Effects of experimentally induced maternal hypothyroidism

Bancroft JD, Cook HC (1994) manual of histological techniques and their diagnostic application. Churchill Livingstone, Edinburgh, London, New York, Tokyo. 1994; Pp. 23-26.

Cano-Europa E, Blas-Valdivia V, Franco-Colin M, Angel Gallardo-Casas C, ocio Ortiz-BR. (2011) Methimazole-induced hypothyroidism causes cellular damage in the spleen, heart, liver, lung and kidney. Acta histochemica 113: 1-5
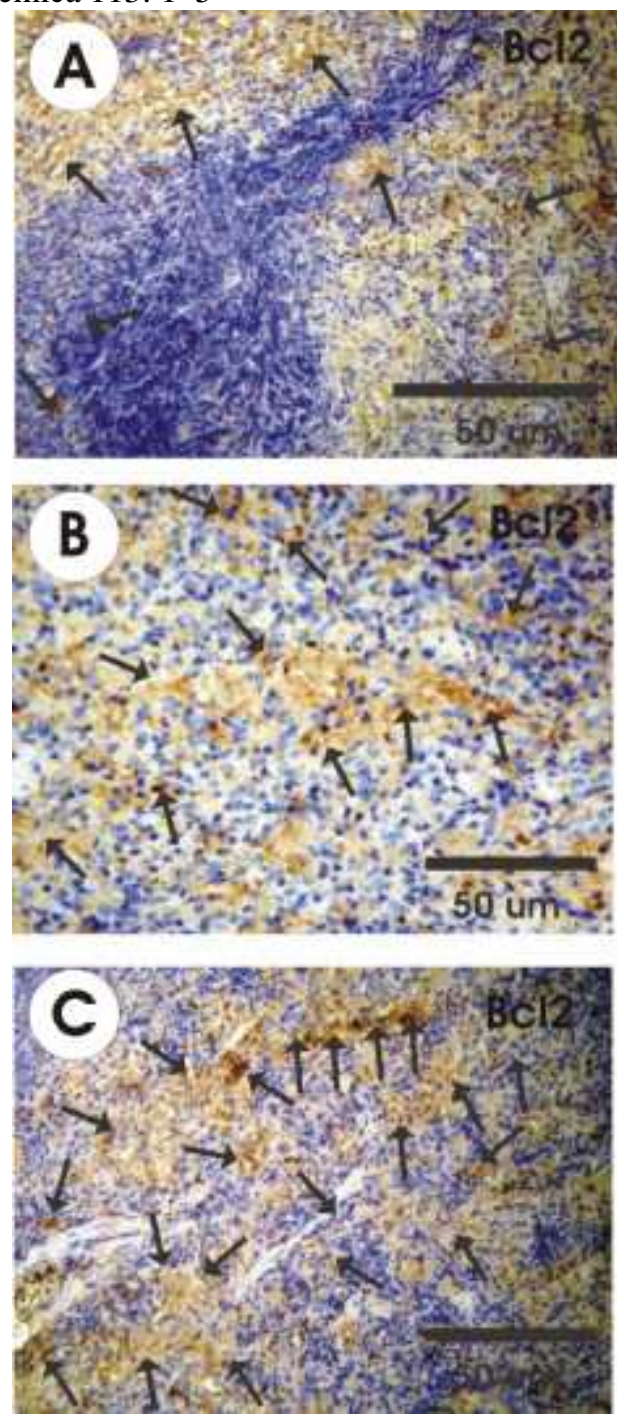

Figures 6(A-C): A-C High power micrographs of the spleen sections of rat stained by $\mathrm{BCl} 2$-ir. A: Marked positive reactions for $\mathrm{BCl} 2$-ir (grade 4) in control rat spleen section. B: Mild positive reactions for $\mathrm{BCl} 2$-ir (grade 2) in hypothyroid rat spleen section. C: Moderate reactions for $\mathrm{BCl} 2$-ir (grade 3) in hyperthyroid rat spleen section. 

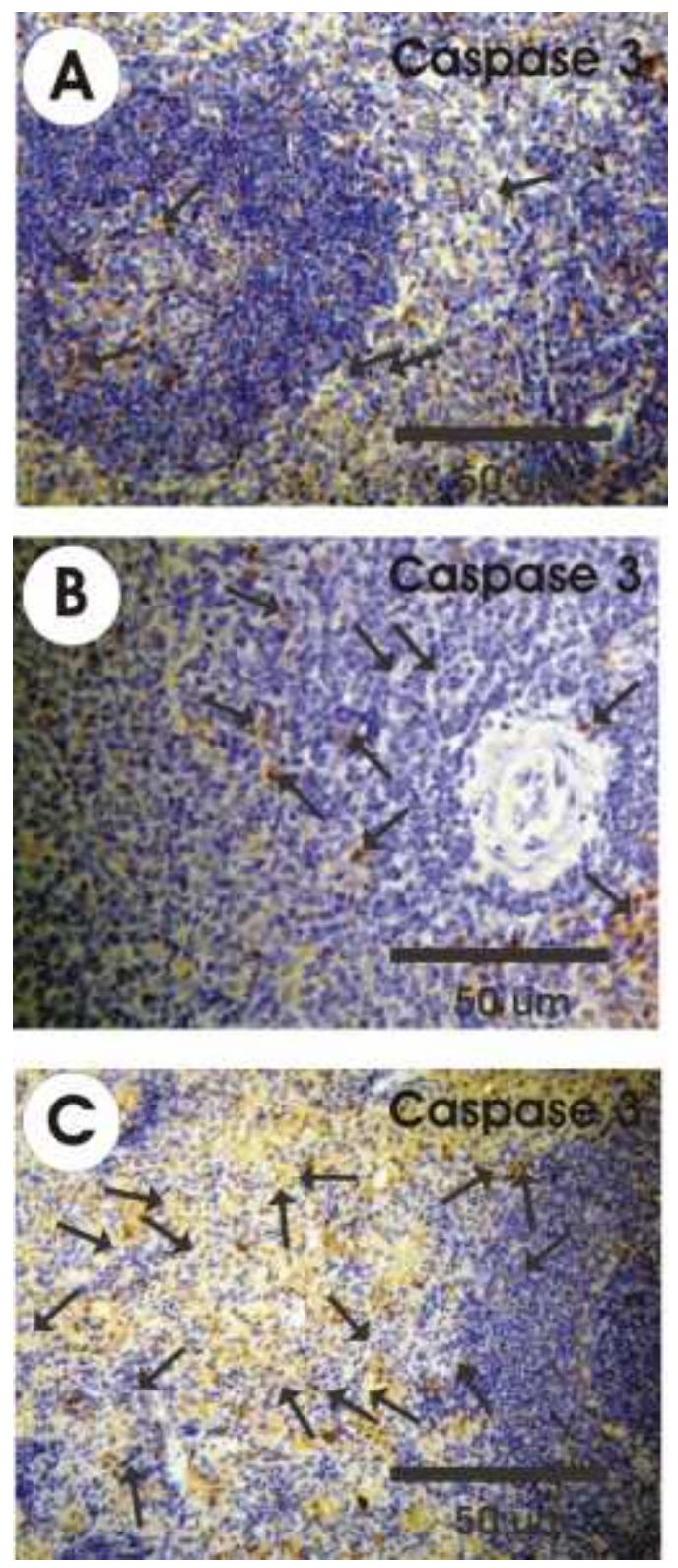

Figures 7(A-C): A-C High power micrographs of the spleen sections of rat stained by Caspase3-ir. A: Faint Caspase3-ir positive reaction (grade 1) in control rat spleen section. B: Mild Caspase3-ir positive reaction (grade 2) in hypothyroid rat spleen section. C: Marked positive reactions for Caspase3-ir (grade 4) in hyperthyroid rat spleen section.

Cano-Europa E, Perez-Severiano F, Vergara P, Ortiz-Butron R, Rios C, Segovia J, et al. (2008) Hypothyroidism induces selective oxidative stress in amygdala and hippo- campus of rat. Metab Brain Dis 23: 275-287.

Collavin L, Lunardi A, Del-Sal G. (2010) p43family proteins and their regulators: hubs and spokes in tumor suppression. Cell death and differentiation 17: 901911.
Cory S and Adams JM (2002) The Bcl2 family: regulators of the cellular life-or-death switch. Nature Reviews Cancer 2: 647-656.

Cory S, Huang CSD, Adams MJ. (2003) The Bcl-2 family: roles in cell survival and oncogenesis. Oncogene 22: 8590-607.

Degterev A. (2003) A decade of caspases. Oncogene, 22 8543-8567

Diebold J, Baretton G, Felchner M, Meier W, Dopper K, Schmidt M, Lohrs U. (1996) Bcl-2 expression, p53 accumulation, and apoptosis in ovaria carcinomas. Am J Clin Pathol. 105:341-34.

Elmore, S. (2007) Apoptosis: A Review of Programmed Cell Death. Toxicol. Pathol., 35: 495.

Fulda, S. et al. (2006) Extrinsic versus intrinsic apoptosis pathways in anticancer chemotherapy. Oncogene, 25: 4798-4811

Gandrillon O, Ferrand N, Michaille J-J, Roze L, Zile MH, Samarut J. (1994) c-erbAa/T3R and RARs control commitment of hematopoietic self-renewing progenitor cells to apoptosis or differentiation and are antagonized by the v-erbA oncogene. Oncogene. 9:749 -758.

Gilbert ME, Paczkowski C (2003) Propylthiouracil (PTU) induced hypothyroidism in the developing rat impairs synaptic transmission and plasticity in the dentate gyrus of the adult hippocampus. Dev Brain Res 145: 1929.

Glantz LA, Gilmore JH, Lieberman JA, Jarskog LF (2006) "Apoptotic mechanisms and the synaptic pathology of schizophrenia". Schizophr. Res. 81 (1): 47-63.

Hafez E, Tousson E (2014) Thyroxine-induced cardiac hypertrophy: Role of ascorbic acid in treatment. Biomedicine \& Aging Pathology 4 (2014)

Huang, Q., et al. (2011) Caspase 3-Mediated Stimulation of Tumor Cell Repopulation During Cancer Radiotherapy. Nature Medicine. 17: 860-866.

Ibrahim W, Tousson E, Ali EM, Mansour MA (2011) Folic acid alleviates oxidative stress and hyperhomocysteinemia involved in testicular dysfunction of hypothyroid rats. General and Comparative Endocrinology, 174: 143-149.

Ibrahim W, Tousson E, El-Masery T, Arafa N, Akela M (2012) The effect of folic acid as an antioxidant on the hypothalamic monoamines in experimentally induced hypothyroid rat. Toxicology and Industrial Health, 28(3) 253-261

Ishizuya-Oka A (1996) Apoptosis of larval cells during amphibian metamorphosis. Microsc Res Technol. $34: 228-235$.

Lo'pez-Torres M, Maria R, Barja G (2000) Effect of hormones on mitochondrial oxygen free radical production 
andDNA oxidative damage in the rat heart. Mol Cell Endocrinol 168: 127-34.

Maes M, Mommen D, Hendrickx D, Peeters D, D' Hondt P, Ranjan R. (1997) Components of biological variation, including seasonality, in blood concentrations of TSH, TT3, FT4, PRL, cortisol and testosterone in healthy volunteers. Clinical Endocrinology; 46: 587-98.

Mahfoud M, Boumend A, Chouabiaa A, Klibetb F, Cherif Abdennoura,Mohamed Salah Boulakouda, El Fekir A (2010) Influence of thyroid dysfunction on liver lipid peroxidation and antioxidant status in experimental rats. Experimental and Toxicologic Pathology 62: 301-310

Mandel SJ, Brent GA, Larsen PR. (1993) Levothyroxine therapy on patients with thyroid disease. Ann Intern Med 119: 492-502.

Mihara, M., Erster, S., Zaika, A., Petrenko, O., Chittenden, T., Pancoska, P. and Moll, U. M. (2003) p53 has a direct apoptogenic role at the mitochondria. Mol. Cell 11, 577-590.

Mohamed TM, Tousson E, Beltagy DM, El Said AS (2014) Biochemical studies in experimentally inducedhyperthyroid rats treated with folic and ascorbic acid. Biomedicine and Biotechnology,2 (4): 60-65.

Oppenheimer JH, Schwartz HL, Strait KA. (1996) The molecular basis of thyroid hormone actions. In: Werner and Ingbar's the thyroid, 7th ed. Braverman LE, Utiger RD, eds. Philadelphia: Lippincott-Raven; 162-184.

Porter AG (2006) Flipping the safety catch of procaspase-3. Nature Chemical Biology, Vol. 2 November 10, 2006.

Salama AF, Tousson E, Ibrahim W, Hussein MW. (2013) Biochemical and histopathological studies in the PTU-induced hypothyroid rat kidney with reference to the ameliorating role of folic acid. Toxicology and Industrial Health; 29(7):600-608.

Scorrano L, Korsmeyer SJ (2003) "Mechanisms of cytochrome c release by proapoptotic BCL-2 family members." Biochem Biophys Res Commun 304(3): 437 44.

Shibutani M, Woo GH, Fujimoto H, Saegusa Y, Takahashi M, Inoue K, Hirose M, Nishikawa A (2009) Assessment of developmental effects of hypothyroidism in rats from in utero and lactation exposure to anti-thyroid agents. Reprod Toxicol 28: 297-307.

Sternberger LA (1979) The unlabelled antibody peroxidase- antiperoxidase (PAP) method. In: "immunocytochemistry", $2^{\text {nd }}$ edn., (Cohen S, and McClusky RT.ed.). John Wiley and sons, New York; 1979. pp: 104-69.

Tata JR (1994) Hormonal regulation of programmed cell death during amphibian metamorphosis. Biochem Cell Biol. 72:581-588.
Thakur C, Saikia T, Yadav R (1997) Total serum levels of tiiodothyroninr (T3), thyroxine(T4) and thyrotropine (TSH) in school going children of Dibrugarh district: an endemic Goitre region of Assam. Indian J Physiol Pharmacol. 41: 167-70.

Toshihiro I (2009) Thyroid hormone and atherosclerosis Vascular Pharmacol J doi:10.1016/j.vph.09.004

Tousson E, Ali EM, Ibrahim W, Mansour MA (2011a) PCNA as a Molecular Biomarker for Spermatogenesis in PTU- Induced Hypothyroidism of Rats. Reproductive Sciences, 18(7) 679-686.

Tousson E, Alm-Eldeen A, El-Moghazy M (2011b) p53 and Bcl-2expression in response to boldenone induced liver cells injury. Toxicology and Industrial Health, 27(8) 711-718.

Tousson E, Ali EM, Ibrahim W, Ashraf RM (2012a) Histopathological and immunohistochemical alterations in rat heart after thyroidectomy and the role of hemin and ketoconazole in treatment. Biomedicine \& Pharmacotherapy. 66 (2012) 627-632.

Tousson E, Ali EM, Ibrahim W, Mansour MA (2012b) Treatment with folic acid ameliorated the histopathological alterations caused by propylthiouracilinduced hypothyroid rat testes. Toxicology and Industrial Health, 28(6): 566-576

Tousson E, Ibrahim W, Arafa N, Akela MA (2012c) Monoamine concentrations changes in the PTU induced hypothyroid rat brain and the ameliorating role of folic acid. Human \& Experimental Toxicology. 31(3) 282-289.

Tousson E, Beltagy DM, Abo Gazia M, AlBehbehani B. (2012d) Expressions of P53 and CD68 in mouse liver with Schistosoma mansoni infection and the protective role of silymarin. Toxicology and Industrial Health, DOI: 10.1177/0748233712442733.

Tousson E, Hafez E, Massoud A, Sweef O, Atta N (2013) Protective role of folic acid in thyroxine-induced cardiac hypertrophy in hyperthyroid rat. Biomedicine \& Aging Pathology 3 (2013) 89-95.

Tousson E, Alghabban AJM, Abou Harga H (2014a) Thyroidectomy induced hepatic toxicity and possible amelioration by Ginkgo biloba leaf extract. Biomedicine \& Preventive Nutrition, 4(3): 391-397.

Tousson E, Atteya E, El-Atrash E, Jeweely OI. (2014c) Abrogation by Ginkgo Byloba Leaf Extract on Hepatic and Renal Toxicity Induced by Methotrexate in Rats. Journal of Cancer Research and Treatment, 2(3): 4451.

Tousson E, Hafez E, Zaki S, Gad A (2014d) P53, Bcl-2 and CD68 expression in response to amethopterininduced lung injury and ameliorating role of 1-carnitine. Biomedicine \& Pharmacotherapy, 8(5): 631-639. 
Tousson E, Hegazy M, Hafez E, Ahmed EA. (2014b) The Effect of L-carnitine on Amethopterin-induced Toxicity in Rat Large Intestine. Journal of Cancer Research and Treatment, 2(3): 55-63.

Wang L, Bowman L, Lu Y, Rojanasakul Y, Mercer RR, Castranova V, Ding M (2005) Essential role of p53 in silica-induced apoptosis. Am J Physiol 288: 488-96.

Woeber KA (2002) Methimazole-induced hepatotoxicity. Endocr Pract 8: 222-224.

Yonish-Rouach E, Grunwald D, Wilder S, Kimchi A, May E, Lawrence JJ, May P, Oren M (1993) P53mediated cell death: relationship to cell cycle control. Mol Cell Biol 13: 1415-1423. 